\title{
Water transit times and solute composition where trees root into bedrock
}

\author{
JENNIFER L. DRUHAN ${ }^{1}$, ALLISON TUNE ${ }^{2}$, LOGAN
} SCHMIDT $^{2}$, W. JESSE HAHM ${ }^{3}$, DAVID N. DRALE ${ }^{4}$, DANIELLA M. REMPE ${ }^{2}$

${ }^{1}$ Department of Geology, University of Illinois UrbanaChampaign, IL, USA (jdruhan@illinois.edu)

${ }^{2}$ Department of Geological Sciences, Jackson School of Geosciences, University of Texas at Austin, TX, USA (alisontune@utexas.edu, loganmschmidt@utexas.edu, rempe@jsg.utexas.edu)

${ }^{3}$ Department of Geography, Simon Fraser University, BC, Canada (whahm@sfu.ca)

${ }^{4}$ Department of Geology, Sacrameto State University, CA, USA (david.dralle@csus.edu)

In forested uplands, precipitation infiltrates soil and weathered bedrock to become the source for headwater streams. The flowpaths and reactive potential of this water should therefore determine stream chemistry. How, where, and to what extent deeply rooted trees regulate these transport and chemical processes has yet to be systemtically resolved. Here we use a novel Vadose Zone Monitoring System (VMS) installed in the Eel River Critical Zone Observatory (ERCZO) to demonstrate that the deep bedrock rhizosphere plays a pivotal role in the location and rates of chemical weathering reactions within the hillslope, thus dictating the solute composition of headwater streams.

Through unique monitoring and simulation capabilites, we highlight the role of three key mechanisms by which vegetation alters fluid composition within the deep bedrock rhizosphere. First, deep roots seasonally extract water many meters below soil and thus uniquely alter the storage volumes and transit times of fluids throughout the hillslope. Second, the dynamic hydrology of the bedrock rhizosphere controls the volume and connectivity of pore space open to gases, and consequently the fluxes of reactive $\mathrm{O}_{2}$ and $\mathrm{CO}_{2}$ across the vadose zone. Third, root-driven transport and respiration of organic carbon and the attendant fluxes of $\mathrm{CO}_{2}$ and $\mathrm{O}_{2}$ below soil impart reactivity to fluids migrating through the vadose zone. In summary, effective simulation of the chemical evolution of water within a catchment requires a representation of the impacts of deep root carbon dynamics and water uptake on both fluid reactive potential and residence time. 